\title{
11 Principles Every Educational Organization Should Be Implementing
}

\author{
Mohamad Chamas ${ }^{1,2^{*}} \quad$ Bassam Hussein $^{2} \quad$ Irina Polonik $^{1}$ \\ 1.Department of Marketing, Belarusian National Technical University, Minsk, Nezavisimosty Ave., 65220013 , \\ Belarus \\ 2.Department of Industrial Engineer, Lebanese International University, Mouseitbeh - PO Box: 146404 Mazraa, \\ Lebanon \\ * E-mail of the corresponding author: mohamed.shamas@libnor.org
}

\begin{abstract}
Many articles and reports issued by educational institutions and research centers discussed the basic requirements that should be implemented by universities, schools, vocational schools, training centers and other categories of educational institutions to assure they can provide quality of education. Although these references have been widely used to achieve quality in education, still differences in requirements may exist. Hence the importance of shedding lights on the International standards ISO 21001 published in 2018 by the International Organization for Standardization. In this article, the author highlighted on the implementation of 11 principles of quality education stipulated in this Standard. In this context, he touched upon the social responsibility principle and the related 7 core subjects (building a governance system, the rights of learners, practicing in a fair operating way, students issues, the development of community, protecting the environment, administrative and academic staff practices) (ISO 26000: Guidance on social responsibility, 2010) that distinguish the ISO 21001 from other international standards and made it a tool that could be applied by educational institutions to create their shared value strategies. In this context, the authors heard the voices of instructors and analyze their views concerning the implementation of the twenty-three requirements mentioned in the ISO 21001, through diffusing surveys to instructors working in educational organizations in Lebanon. The results indicated that 19 of the requirements are being applied effectively.
\end{abstract}

Keywords: Standard, Social Responsibility, Quality Education, Shared Value

DOI: $10.7176 / \mathrm{JEP} / 12-33-01$

Publication date: November $30^{\text {th }} 2021$

\section{Introduction}

Achieving quality of education is a critical topic discussed worldwide. Thus the International Organization for Standardization published a new international standard related to this topic. But one of the important questions that could be raised: Can the quality in education be standardized? The answer is yes. Standards are everywhere; we are living in a world full of standards. The measurement units used worldwide are the same, so they are a kind of standards. The franchising system adopted by the businesses that enforce the franchisee to comply with the same requirements is also a kind of standardization. Many other examples such as the ERP software, the accountability principles, the protocols for taking samples to diagnose the COVID 19, are also kind of standards. These examples are a reason that standards can be related to any sector, and they support the importance of having a standard that specify the minimum requirements for building a management system at educational organizations that assure the provision of high quality of educational services.

The international organization for standardization ISO published more than 30,000 standards covering a broad range of sectors. The standard is defined as voluntary documents that specify the characteristics of a product, or service. One of the critical and important international standard is the ISO 9001, that provide a broad platform and minimum requirement to implement a quality management system in all type of organizations. (ISO 9001: Quality management system - Requirements, 2015). More than 2 million institutions worldwide from different sectors implemented this standard that makes it very famous. However, the educational sector made up the lowest percentage in the application of this standard.

\section{Literature review}

\subsection{Comparison between ISO 9001: 2015 and ISO 21001: 2018}

The International Standard ISO 9000 published in 2005 and that explains the terminology used in the ISO 9001 , define quality as the capability of a group of ingrained characteristics of products, services, systems, processes, to achieve the requirements of customers.( (ISO 9000: Quality management system - Fundamentals and Vocabulary, 2005). A study was conducted in 2017 to find out what are the obstacles that face the implementation of a quality management system in the educational institutions. (Hussein et al., 2017). The most prominent was

First: the terminology used in ISO 9001 that is more convenient for business and not educational services. 
The vocabulary used in the standard is suitable for use in the non-educational sectors, for example, when the international standard mentions the word customers. This word cannot be used in the educational sector. As the student's relationship with educational institutions is distinctive, punctuated by many interactions, the relationship goes beyond the definition of a customer. The educational institutions build generations and build cultures and societies.

The second point is the Lack of awareness. Educational institutions indeed carry out scientific research continuously, and it is also true that many educational institutions work with standardization body in their countries to contribute to the issuance of standards, but there remain a large number of educational institutions that do not know that there are standards related to quality in education that can benefit from their implementation. Some believe that the standards are only for industrial products and their use is limited to factories. However, this statement is incorrect, as the standards can be related to any sector.

The third point is the existence of the accreditation system that made educational institutions think it could replace the quality system and thus it is an additional effort and waste of time to implement a quality management system, but in fact, the two topics are completely different. The accreditation system assures that the department accredited is competent to give the educational service, on the other hand, the accreditation requirements may not cover all the requirements of a quality management system that may cover the whole educational institution.

The fourth point is the commitment of the top management. Looking from a pragmatic point of view, the quality management system could not be implemented without the commitment of top management. The international standard has defined the role of top management as responsible for setting up a strategy for the institution through which he guarantees all the effective implementation of the principles of a quality management system.

The fifth point is Time management. Most of the educational organizations are submerged under the pressures of daily educational tasks. Consequently, they will think that building a management system will be an additional burden that they will not be able to secure sufficient time for. Ultimately, however, educational institutions have to know that a quality management system leads to effective time management

The sixth point is Resources availability: The availability of resources is a strategic issue for any institution. There is no doubt that the global economic recession is putting pressure on all sectors that have started to suffer from a scarcity of resources, especially in the crisis of the Covid 19 pandemic, which made many workers unemployed and thus unable to pay their tuition fees or the tuition of their children, and thus educational institutions began to austerity. But educational institutions should know that the investment in implementing the international standard is a form of long term investment that brings values.

The seventh point is the auditing guidelines: the main question that arises. Who will audit these standards and according to which guidelines? The international standard ISO 19011 provide a guideline for auditing a quality management systems in all its stages and also specifies the characteristics that an auditor or audit team or persons managing the audit programme must possess, as well as provide a guidance on the evaluation of their competences. (ISO 19011: Guidelines for auditing management systems, 2018) But the 2 questions that arise:

The educational organizations are part of the organizations covered by the ISO 19011 scope?

The external auditors trained on the principles of the international standard - ISO 9001 are able to perform the audit at the educational institutions?

The answer is conditional on the auditor's competence, experience, and knowledge of educational matters and of the core subjects of social responsibility as a whole. Consequently, conducting an audit at educational institutions to ensure their compliance with the requirements of educational organization management system is completely different from auditing an institution against the requirements of the international standard ISO 9001. This in itself is an inevitable challenge and calls for issuing a new international standard on the issue of quality in educational institutions, and this is what the International Organization for Standardization started to do.

Based on the foregoing, and since the international standard ISO 9001 did not meet the aspirations of the educational institutions, it was necessary to have another international guide on the application of quality in educational institutions in which it takes into account the objectives and values of educational process, their impact on building generations, and the positive economic impact from universities to close community through the supply of human capital and innovation. (Valero and Van Reenen, 2019) and thus takes into account the principles of social responsibility. The international organization for standardization had to take the initiative and issued a new standard ISO 21001 on May 2018.

This international standard indicates generic requirements for a management system for educational organizations (EOMS). (ISO 21001: 2018 Educational organizations - Management systems for educational organizations - Requirements with guidance for use, 2018)

It has been 3 years and a half since the international standard was published; it is a short time to assess the situation and to know how many institutions will implement it in comparison with the ISO 9001 that was issued more than 35 years. 
Although it is expected that the international standard - ISO 21001 will be implemented in educational organization more than the ISO 9001:2015, especially that ISO 21001 deals with the seven factors mentioned above (terminology, lack of awareness, accreditation system, time management, resource availability, auditing, the commitment of top management) and was specific to educational institutions. So, in order to overcome future obstacles that may prevent the application of the international standard ISO 21001:2018, the educational organizations and national standards body should cooperate and should know that they are closely related to each other. Firstly, National standards are issued through technical committees formed by national standards bodies, and the largest number of stakeholders concerned with the subject matter of the standard are invited, whether from the public or private sectors, for example, but not limited to the academic sector, which is represented by educational institutions that can enrich discussions through scientific studies that they carry out.

Therefore the more the educational institutions are stronger; the discussions during the issuance of the standards have more credibility, just as standards bodies can rely on scientific research and innovations issued by the educational organization to convert them into standards. (Standards, n.d.)

And vice versa, educational institutions need strong standards bodies, because they can base they can implement these standards into their premises.

The cooperation between the two types of institutions is critical to raise awareness of the issued standards, especially those related to quality, which ultimately leads to a wider application of this standard.

If we want to compare the principles of both international standards ISO 9001 and ISO 21001, the main difference rely on the social responsibility part that exists in the ISO 21001 as mentioned in table 1.

Table 1: Comparison of principles between ISO 21001:2018 vs ISO 9001:2015

\begin{tabular}{|c|c|}
\hline Principles related to ISO $21001: 2018$ & Principles related to ISO 9001:2015 \\
\hline a- Emphasizing on students; & a- Hearing the voice of customer; \\
\hline $\begin{array}{l}\text { b- The commitment, vision and responsibility of } \\
\text { leaders }\end{array}$ & $\begin{array}{l}\text { b- The commitment, vision and responsibility of } \\
\text { leaders }\end{array}$ \\
\hline c- Engaging stakeholders; & c- Engaging stakeholders; \\
\hline d- Transform activities into Processes; & d- Describe activities into Processes; \\
\hline $\begin{array}{l}\text { e- To assure an endless improvement of the } \\
\text { implemented management system; }\end{array}$ & $\begin{array}{l}\text { e- To assure an endless improvement of the } \\
\text { implemented management system; }\end{array}$ \\
\hline f- Taking decisions based on facts & f- Taking decisions based on facts \\
\hline $\begin{array}{l}\text { g- Relation between the management, students and } \\
\text { other stakeholders; }\end{array}$ & $\begin{array}{l}\text { g- Relation between the management, customers and } \\
\text { other stakeholders ; }\end{array}$ \\
\hline \multicolumn{2}{|l|}{ h- To be socially responsible; } \\
\hline \multicolumn{2}{|l|}{ i- To assure accessibility and equity; } \\
\hline \multicolumn{2}{|l|}{ j- Ethical behavior in education; } \\
\hline k- Securing and protecting the Data & \\
\hline
\end{tabular}

\subsection{ISO 21001 principles every educational organization should know}

In the above table, we can see that ISO 21001 contains 11 principles. Seven principles are common to the ISO 9001 and four are new.

The seven common principles are related to:

2.2.1 Emphasizing on students

In the International Standard - ISO 9001, the first principle is related to focusing on customers, which means understanding their requirements. As for the new standard ISO 21001, it means understanding learners' requirements as well as all stakeholders' one and trying to include them in the strategy.

2.2.2 Having leadership vision

This principle reflects the responsibility of the top management responsibility toward their commitment to assure an effective implementation of the management system and toward the continual support they should provide through planning, communication and securing resources.

2.2.3 Engagement of stakeholders

This third principle is related to hear the voices of the stakeholders in order to identify their requirements and try to engage them. Educational institutions are not just an educational edifice whose role ends when teaching students, but rather has a much greater role. They have a societal mission in building generations and building cultures that will directly affect the surrounding societies by solving labour market problems in the event that new specializations are introduced that the market needs and thus developing the economy, In addition they have a role in finding solutions to environmental, social problems through scientific research. Consequently, educational institutions need to hear the voices of all the parties involved in the educational institution and understand their needs. (Besterfield, Besterfield-Michna, Besterfield and Besterfield-Sacre, 1995) and try to engage stakeholders in the decisions that could influence them. 


\subsubsection{Transform activities into Processes}

Transforming educational activities into processes and procedures is the basis for building a quality management system in educational institutions. Linking activities together gives a clear picture of how this system can be adjusted

\subsubsection{Endless improvement}

What is the benefit of implementing a quality management system in educational institutions if there is no continuous improvement of the management system that ensures the quality of the educational process? Achieve the Kaizen or the continual improvement at the educational institutions is the a guarantee to raise the quality bar of the educational services.

2.2.6 Taking decisions based on evidence

One of the principles of management systems is to take decisions based on evidence and facts.

2.2.7 Relation between the management, students and other stakeholders

The educational organization shall ensure that a fruitful relationship exists between decision-makers and all academic and administrative employees and workers. The relationship should also exist between the educational organization and stakeholders. This relationship should be clear and based on 2 ways communications to ensure that stakeholder's requirements are well identified, and the risks and opportunities are analyzed and clear enough to plan a good strategy that identifies the SMART objectives to achieve. Nowadays, good and concrete relationship management is a tool for the success of any educational organization.

\subsection{Principles Related To Social Responsibility}

Basically, the 3 additional principles mentioned in ISO 21001:2018, equity, ethical behaviour in education and securing and protecting data are part of the social responsibility concept.

Social responsibility! Here is the bottom line...

It took a lot of discussions worldwide as a concept. There are many definitions of social responsibility issued by professors, international references such as the European Union. The famous definition was issued by the European Union in 2002 (Corporate Social Responsibility: A business contribution to Sustainable Development, 2002). However, in order to be based on the latest definition, it was necessary to refer to the international standard ISO 26000 published in 2010 "Guidance on social responsibility" that holds the company responsible for the impact of its decisions on the society, economy and environment and encourage them to hear the voices of their stakeholders and working in an ethical behaviour way in order to achieve sustainable development. (ISO 26000: Guidance on social responsibility, 2010)

The important questions that arise:

1- Is it really an option for educational institutions to be socially responsible?

Social responsibility for an educational institution is not an option it is a must so the question should be how educational institution is going to manage their work to be socially responsible?

The imposition of social responsibility as one of the eleven principles in the international standard ISO 21001:2018, made it radically distinguished from the international standard ISO 9001. While ISO 9001 is counted as operational effectiveness or best practices tool used to organize the management system inside the organization, the ISO 21001 could be seen as a document that pushes the educational institution to adopt a unique strategy that creates "shared value" (Porter and Kramer, 2011) which is seen as competitive advantage for the organization and could bring benefits and value to the economy and society in which the organization operates.

Although educational institutions have a business model as any institutions, however, these models should be unique for many reasons. Educational service is not a normal service with limited influence, the output of the educational process has a huge influence on the community.

\subsection{The Core Subjects of Social Responsibility}

The main challenge of the ISO 21001 is to follow the principle of ISO 26000 represented by the seven core subjects listed below:

- Building a governance system into the educational organization

- The rights of students and learners

- Administrative and academic employees practices

- Protecting the environment

- Practicing in a fair operating way

- The issues related to students and learners

- The involvement and development of the community

2.4.1 Building a governance system into the educational organization

An educational organization should develop a shared value strategy that aim to prove the responsibility of the 
decision makers in the educational organization toward using the financial, natural, social, intellectual and human resources efficiently and toward hearing the voices of stakeholders who could be the instructors, learners, guardians, directors and other categories through a clear communication procedure.. (ISO 26000: Guidance on social responsibility, 2010). The decision makers shall ensure that decisions are implemented and followed in a socially responsible way.

2.4.2 The rights of students and learners

Educational organization has the responsibility to respect the rights of its stakeholders within its sphere of influence especially the learners. One of these rights is to receive a quality education. The educational organization shall support students and enhance communication with them (Yolkin, 2020), and evaluate their satisfaction. Concerning the evaluation of satisfaction of learners, the educational organization should be aware and pay attention that educational organization should not compromise on the shared value that they are creating or on quality of education. (ISO 26000: Guidance on social responsibility, 2010)

2.4.3 The development and involvement of community

The educational organizations and communities where they operate are interrelated. The educational organization should involve the community for example through building a relationship, developing education and skills programs; preserving culture and arts; providing learners with health services. (ISO 26000: Guidance on social responsibility, 2010). Developing communities should be the main mission of educational institutions and could be done by the educational organization itself through redefining primary and secondary activity in its value chain.

\subsubsection{Students' issues}

Basically the original term used by the international standard ISO 26000 which is a reference of the ISO 21001 is "consumer" but it is not recommended to be used in our case. The consumers here are the students or learners. The educational organization has to promote its educational services through fair marketing, and they should ensure that relation between educational institutions and students is based on fair practices. Educational organizations have to protect Students' health and safety and should promote sustainable development practices whether internally or externally. (ISO 26000: Guidance on social responsibility, 2010) An educational organization's role arises from building the culture of sustainable consumption for learners, who will, later on, impact their societies.

2.4.5 Environment

The world is changing, the population is increasing and the natural resources are decreasing, we are living in a transition zone. There are 2 consequences; either we will breakdown through more pollution, global warming, and the collapse of the ecosystems or we will break through radical innovation. It is very critical that an educational institution helps to ensure that resources per person become sustainable and to provide solutions to eliminate unsustainable volumes and patterns of production. Educational institutions bear a huge responsibility toward building capacity in promoting the development of sustainable societies and lifestyles. (ISO 26000: Guidance on social responsibility, 2010)

The environmental responsibility of educational institutions is divided into two parts:

- The first part is an internal responsibility related to implementing an environmental management system inside the educational organization through evaluating environmental performance, quantifying and reporting greenhouse gas emissions, assessing life cycle, designing environmental label and environmental communication. Here, too, the close relationship between the national standards Institution and the educational institutions appears, so that one of the most important standards that exist is related to environmental management system bearing the number ISO 14001. (ISO 26000: Guidance on social responsibility, 2010)

- The second responsibility is external, which is broader and has the ability to influence society by building generations that appreciate the importance of protecting the environment. It can be achieved through the inclusion of new curriculum or assigning graduation projects related to environmental topics and through participating in scientific studies, research and issuing scientific articles, in addition to building capacity and organizing conferences and workshops.

2.4.6 Practicing in a fair operating way

The educational organizations have to use their relationships to promote the adoption of social responsibility more broadly throughout the organization's sphere of influence, and they should act in the presence of their competitors in a socially responsible way (ISO 26000: Guidance on social responsibility, 2010)

2.4.7 Administrative and Academic Staff Practices

The practices of educational institutions towards the rights of administrative and academic employees, whether full-time or part-time, is one of the pillars of social responsibility that secures high-quality education in the event that the standards issued by the International Labor Organization are respected, especially in terms of justice in the salaries of administrative and academic employees and other workers in educational institutions. This core subject also covers the right of labors to participate in discussing the content of any agreement or procedures that 
influence their careers, for example: health coverage, capacity building, working time, wages, any possibility of relocation, and their rights to discuss disciplinary and grievance procedures in addition to other rights; (ISO 26000: Guidance on social responsibility, 2010)

\subsection{Social responsibility practices}

The educational organizations could develop a new curriculum that meets the market needs and leads to create jobs and therefore helps in human development and improving standards of living through full and secure employment. Ultimately it leads to co-create wealth.

During the Covid 19 pandemic, most of the educational institutions closed and shifted to e-learning. So the use of information and communication technology and many social media programs helped the educational institution to teach their students through distance learning. (He and Harris, 2020)

Thanks for the ICT products that make this feasible. However, how are we controlling the quality of educational services provided to learners? And how we assure that equity exists and that all learners have the access to join distance learning?

How to assure that guardians or learners are still able to pay the tuition fees in this black swan caused by this pandemic that lead to economic depression worldwide?

Some educational systems as the English one, help students in their living expenses and the loan system ensure that tuition fees are not paid up front. (Murphy, Scott-Clayton and Wyness, 2019)

This challenging economic period is putting pressure on the educational institution and on the society itself, and since both of them are interdependent, they will impact each other. The only solution is to go through innovation and create a solution that brings benefits to society and educational institutions at the same time.

The first value an educational organization should create is co-sharing responsibility with society. Sharing responsibility with society to solve their social, economic and environmental problems through innovative idea. We are not saying here that educational institution is responsible to solve all social problems. It is a common responsibility; however, educational institutions can participate in the solution of a huge part of societal issues through their value chains. Educational institutions could build a healthy generation and diffuse the right information that brings benefits to their students, who in their turn will influence their parents and their communities. Society needs a successful educational institution. At the same time, society needs the educational institution to be strong in order to open opportunities to the competent persons to teach at their premises and to be confident that their children will receive the right knowledge.

\section{Methodology}

This study is based on quantitative analysis based on studying the filled surveys from one main category of stakeholder "teachers" covering the following categories of educational organizations:

- Vocational schools, schools and universities

The survey was based on 5 sections: Innovation, Business model, industrialization, academic capitalism and finally quality.

The quality sections include 23 criteria as below. (ISO 21001: 2018 Educational organizations — Management systems for educational organizations - Requirements with guidance for use, 2018)

- Defining, evaluating and prioritizing stakeholders' requirements

- Hearing the voices of students and learners

- Developing a quality policy

- Communicating the policy to stakeholders

- Setting additional requirements for special needs education

- Identifying organization objectives and planning to achieve them

- Planning of changes

- Taking actions to address risks and opportunities

- Evaluation of satisfaction of learners, other beneficiaries, and staff

- Conducting internal audit

- Developing a management review

- Assure endless improvement

- Provide support for organizational knowledge

- Provide support for human resources

- Provide support for the environment for operating educational processes

- $\quad$ Provide support for facilities

- $\quad$ Building capacity

- Control of delivery and changes of the educational products and services

- Determining the requirements for the educational products and services 
- Communicating the requirements for the educational products and services

- Control of the educational nonconforming outputs

- Design and development of educational products and services

- Teaching the transferrable skills (taking initiatives, taking responsibilities,

- $\quad$ communication skills, cooperation, teamwork, leadership, and problem analysis)

In this article, the authors focus on teachers responses related to quality. So the answers of teachers related to section 5 are analyzed using a simple statistical method.

\subsection{Study Location:}

All categories of educational organizations across the country - Lebanon

\subsection{Study Duration:}

The study has been done during the Academic Year 2019/2020.

\subsection{Sample Size:}

585 responses from teachers.

\subsection{Sample Size Calculation:}

The sample size was determined using the Yamane formula:

$$
\mathrm{n}=\mathrm{N} / 1+\mathrm{N \alpha} 2 \quad \text { (Yamane, 1967) }
$$

Where $\alpha$ is the desired level of precision. With a 95\% confidence level and 5\% precision;

\section{Results}

As shown in figure 1, 19 requirements of the 23 mentioned above could be considered as effectively implemented based on the instructors' answers which is a strong points

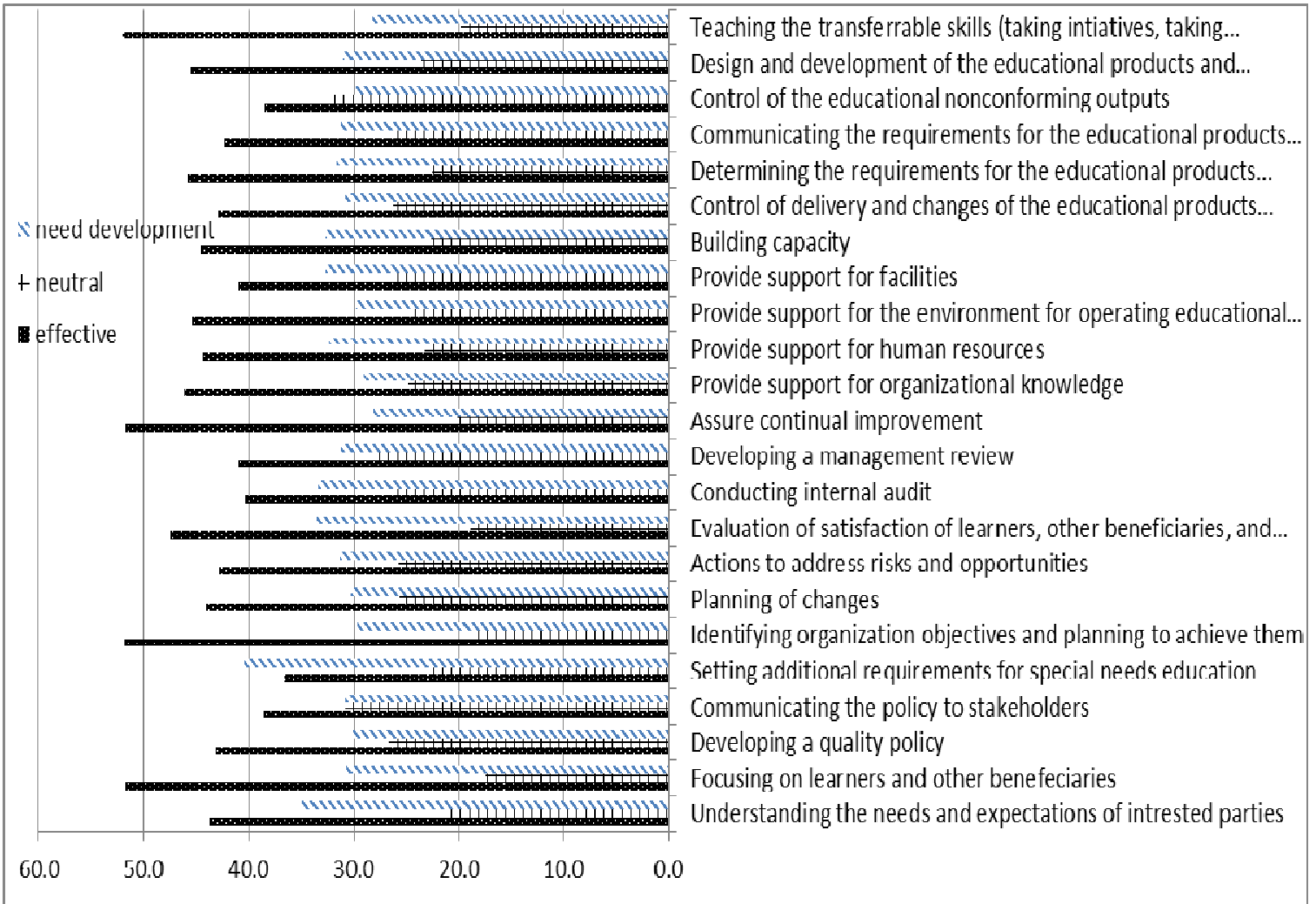

Figure 1: Chart representing the percentage of development of each ISO 21001 requirements

The highest grade was given to "Hearing the voices of students and learners" with $66 \%$ as shown in table 2 . This result shows that leaders of educational organizations are doing well in ensuring that voices of stakeholders are heard, and the requirements of learners are met. It also means that risks and opportunities that could affect the quality of educational services are well addressed. 


\begin{tabular}{|c|c|c|c|c|}
\hline \multirow[t]{2}{*}{ ISO 21001:2018 requirements } & \multicolumn{3}{|c|}{ Instructors } & \multirow[t]{2}{*}{ Grades } \\
\hline & $\begin{array}{c}\text { Need } \\
\text { Development }\end{array}$ & Neutral & Effective & \\
\hline $\begin{array}{c}\text { Defining, evaluating and prioritizing stakeholders' } \\
\text { requirements }\end{array}$ & 27.5 & 11.1 & 61.4 & $4^{\text {th }}$ grade \\
\hline Hearing the voices of students and learners & 26.0 & 8.0 & 66.0 & 1st grade \\
\hline Developing a quality policy & 28.2 & 14.7 & 57.1 & $10^{\text {th }}$ grade \\
\hline Communicating the policy to stakeholders & 30.4 & 21.1 & 48.5 & $20^{\text {th }}$ grade \\
\hline $\begin{array}{l}\text { Setting additional requirements for special needs } \\
\text { education }\end{array}$ & 36.2 & 17.5 & 46.3 & 22th grade \\
\hline $\begin{array}{l}\text { Identifying organization objectives and planning to } \\
\text { achieve them }\end{array}$ & 26.3 & 9.9 & 63.8 & $2^{\text {nd }}$ grade \\
\hline Planning of changes & 28.2 & 13.7 & 58.1 & $8^{\text {th }}$ grade \\
\hline Actions to address risks and opportunities & 28.3 & 18.9 & 52.7 & $15^{\text {th }}$ grade \\
\hline $\begin{array}{c}\text { Evaluation of satisfaction of learners, other } \\
\text { beneficiaries, and staff }\end{array}$ & 31.3 & 16.4 & 52.3 & $16^{\text {th }}$ grade \\
\hline Conducting internal audit & 31.5 & 21.6 & 46.9 & 23th grade \\
\hline Developing a management review & 27.1 & 21.4 & 51.4 & $18^{\text {th }}$ grade \\
\hline Assure continual improvement & 27.0 & 14.6 & 58.4 & $7^{\text {th }}$ grade \\
\hline Provide support for organizational knowledge & 24.8 & 16.6 & 58.6 & $6^{\text {th }}$ grade \\
\hline Provide support for human resources & 27.9 & 20.6 & 51.4 & $17^{\text {th }}$ grade \\
\hline $\begin{array}{c}\text { Provide support for the environment for operating } \\
\text { educational processes }\end{array}$ & 28.1 & 18.1 & 53.8 & $13^{\text {th }}$ grade \\
\hline Provide support for facilities & 27.8 & 18.9 & 53.3 & $14^{\text {th }}$ grade \\
\hline Building capacity & 30.0 & 19.1 & 50.9 & $19^{\text {th }}$ grade \\
\hline $\begin{array}{l}\text { Control of delivery and changes of the educational } \\
\text { products and services }\end{array}$ & 26.8 & 16.8 & 56.4 & $11^{\text {th }}$ grade \\
\hline $\begin{array}{l}\text { Determining the requirements for the educational } \\
\text { products and services }\end{array}$ & 26.7 & 13.7 & 59.6 & $5^{\text {th }}$ grade \\
\hline $\begin{array}{l}\text { Communicating the requirements for the educational } \\
\text { products and services }\end{array}$ & 27.8 & 16.9 & 55.3 & $12^{\text {th }}$ grade \\
\hline Control of the educational nonconforming outputs & 28.7 & 23.3 & 47.9 & 21 th grade \\
\hline $\begin{array}{l}\text { Design and development of the educational products } \\
\text { and services }\end{array}$ & 27.5 & 15.0 & 57.4 & $9^{\text {th }}$ grade \\
\hline Teaching the transferrable skills & 25.6 & 11.6 & 62.8 & $3^{\text {rd }}$ grade \\
\hline
\end{tabular}

Table 2: Percentage of development of each ISO 21001 requirements

The second grade was given to "Identifying organization objectives and planning to achieve them" with $63.8 \%$. This result means that educational organizations are effectively identifying their SMART objectives which are relevant to the conformity of educational services and to the enhancement of learner, staff and other beneficiary satisfaction and they are continually monitored, updated and take into account applicable requirements.

When planning how to achieve its SMART objectives, the educational organization shall determine and outline in its strategic plan the 5 "W".

- What the educational organization have to do?

- What resources will be required?

- Who are the responsible persons?

- When the planned action will be implemented?

- How the educational organization will evaluate the results of the educational organization?

The third grade was given to "Teaching the transferrable skills with $62.8 \%$. This result shows that educational organizations are building the capacity of learners on taking initiatives, taking responsibilities, communication skills, cooperation, teamwork, leadership, and problem analysis.

The fourth grade was given to "Defining, evaluating and prioritizing stakeholders' requirements" with $61.4 \%$

This percentage is a proof that educational organizations are determining the stakeholders that are relevant to them and they are hearing their voices.

Concerning the requirements where there are opportunities for improvement, the results showed that "communicating the quality education policy with stakeholders" receives $48.5 \%$. So it is not only important to 
hear the voices of stakeholders and understand their needs, but also engage the stakeholders.

"Setting additional requirements for special needs education" received $46.3 \%$. This topic is a mandatory issue for any educational institution and reflects the extent of its commitment to follow the principles of social responsibility and secures equity among students. This topic should be reflected in the strategies, objectives, processes and targets of the educational organizations, and should be monitored on continual basis.

"Conducting internal audit" received 46.9\%. The internal audit allows the educational institution to detect the existing gaps and to take corrective action. The educational organization shall conduct internal audits to ensure that its management system is well implemented and comply with the the requirements of the international standard ISO 21001. The educational institution shall have a clear procedure specifying how to plan, establish, implement and maintain an audit programme(s), including the frequency, methods, responsibilities, planning requirements and reporting, which shall take into consideration the objectives of the educational organization management systems, the importance of the processes concerned, the feedback from relevant interested parties, and the results of previous audits.

\section{Conclusion}

One of the challenges that may face the educational organizations during the implementation of ISO 21001 is the financial resources. However many studies related to the economic benefits of the implementation of standards have been done at the macro-level and micro-level, and showed that benefits of countries and institution of implementing standards on growth corresponding to about $0.7 \%$ to $0.8 \%$ of the gross domestic product (The Economic Benefits of Standardization An update of the study carried out by DIN in 2000, 2020). The positive economic impacts of the implementation of international standards related to educational organization management system are expected to extend well beyond the percentage of economic growth mentioned above. Standards are diffusers of knowledge (Economic benefits of standards, 2014), that aim to reduce poor quality such as quality management system standard (Sandholm, 2000). Another example of economic benefits of standards is the ISO 45001 related to occupational health and safety that specify requirements for workplace safety, that lead to reduce the number of occupational accidents and absenteeism, therefore it is a long term investment. (ISO 45001: briefing note - occupational health and safety, 2015). Or the implementation of the environmental standards as ISO 14001 that specifies the requirements for an environmental management system that help protecting the environment, improving the quality of life that will lead to a positive impact on the economy (SMEs, 2020). In this manner, standards relieve the burden on the state.

Based on the above-mentioned, the authors identified clearly the difference between both international standard ISO 9001 which is counted as operational effectiveness or best practices while the ISO 21001 is about creating a shared value strategy, through implementing one or more of the below mentioned three-way:

1- The educational learning process is the main product in the educational organization. The educational organization could "reconceive" (Porter and Kramer, 2011) it through creating an innovative learning process based on new technology and new approach as an accelerated learning process taking into consideration stakeholders' requirements.

2- Educational organization could analyze the decision taken in each activity in the value chain whether primary activities related to (Students enrollment, learning processes, fair marketing, success rate, impact on society and many others) or support activities related to (infrastructure, the technology used, recruiting administrative and academic staff, building competence, research and development, or others) and taking actions that could affect positively the society. Each educational institution could redefine the value chain (Porter and Kramer, 2011), differently from others. For example, but not limited to, some educational organizations can work on productivity levels; others can work on increasing resources efficiency or reducing poor quality cost.

3- Educational institutions have a big role on empowering communities (Porter and Kramer, 2011) by taking society and stakeholders concerns into consideration and through co-creating wealth and through co-sharing responsibility.

The international standard ISO 21001 is a fact. These 11 principles mentioned above make the ISO 21001, a unique standard and differ it from other management system standards. So the future direction of this research is to know how the educational institution will implement it and how they will integrate all the 11 principles mentioned above. It is a huge job that requires joint efforts to build a shared value strategy and create an innovative business model (Osterwalder and Pigneur, 2011).

\section{References}

2010. ISO 26000: Guidance On Social Responsibility. 1st ed. Switzerland: International organization for standardization.

2015. ISO 9001: Quality Management System - Requirements. 5th ed. Switzerland: International organization for standardization.

Hussein, B., Abou Nassif, S., Aridi, M., chamas, M. and Khachfe, H., 2017. Challenges and Prospects of 
Implementing ISO 9001:2015 in Lebanese Higher Education Institutions. Journal of Resources Development and Management, 33.

2018. ISO 19011: Guidelines For Auditing Management Systems. 3rd ed. Switzerland: International Organization for Standardization.

Valero, A. and Van Reenen, J., 2019. The economic impact of universities: Evidence from across the globe. Economics of Education Review, 68, pp.53-67.

2018. ISO 21001: Educational Organizations — Management Systems For Educational Organizations Requirements With Guidance For Use. 1st ed. Switzerland: International organization for standardization.

ISO. n.d. Standards. [online] Available at: $<$ https://www.iso.org/standards.html $>$ [Accessed 14 November 2020].

Besterfield, D., Besterfield-Michna, C., Besterfield, G. and Besterfield-Sacre, M., 1995. Total Quality Management. London: Prentice Hall International.

Yolkin, T., 2020. THE EDUCATIONAL PROCESS OF THE BASIC SYSTEM-ACTIVITY APPROACH IN THE PRESCHOOL EDUCATIONAL ORGANIZATION. European Journal of Research and Reflection in Educational Sciences, [online] 8(4), pp.26-29. Available at: <https://www.idpublications.org/wpcontent/uploads/2020/04/Full-Paper-THE-EDUCATIONAL-PROCESS-OF-THE-BASIC-SYSTEMACTIVITY-APPROACH-IN-THE-PRESCHOOL-EDUCATIONAL.pdf $>$ [Accessed 10 November 2021].

Sandholm, L., 2000. Total Quality Management. 2nd ed. Lund: Studentlitteratur.

Iso.org. 2015. ISO 45001: Briefing Note - Occupational Health And Safety. [online] Available at: $<$ https://www.iso.org/files/live/sites/isoorg/files/archive/pdf/en/iso_45001_briefing_note.pdf $>$ [Accessed 15 November 2020].

SMEs, I., 2020. ISO 14001:2015 - Environmental Management Systems - A Practical Guide For Smes. [online] ISO. Available at: <https://www.iso.org/publication/PUB100411.html > [Accessed 15 November 2020].

Eur-lex.europa.eu. 2002. Corporate Social Responsibility: A Business Contribution To Sustainable Development. [online] Available at: <https://eurlex.europa.eu/LexUriServ/LexUriServ.do?uri=COM:2002:0347:FIN:EN:PDF> [Accessed 14 November 2020].

He, H. and Harris, L., 2020. The impact of Covid-19 pandemic on corporate social responsibility and marketing philosophy. Journal of Business Research, 116, pp.176-182.

Murphy, R., Scott-Clayton, J. and Wyness, G., 2019. The end of free college in England: Implications for enrolments, equity, and quality. Economics of Education Review, 71, pp.7-22.

International organization for standardization. (2005). Quality management systems - Fundamentals and vocabulary [Ebook] (3rd ed., p. 7). Retrieved 15 August 2020, from.

Yamane, T. (1967). Statistics: An Introductory Analysis (2nd ed.). Harper and Row.

Porter, M. and Kramer, M., 2011. Creating Shared Value How to reinvent capitalism - and unleash a wave of innovation and growth. Harvard business review,

2005. ISO 9000: Quality management systems - Fundamentals and vocabulary. 3rd ed. 1st ed. Switzerland: International organization for standardization.

Din.de. 2020. The Economic Benefits Of Standardization An Update Of The Study Carried Out By DIN In 2000. [online] Available at: <https:/www.din.de/blob/89552/68849fab0eeeaafb56c5a3ffee9959c5/economicbenefits-of-standardization-en-data.pdf $>$ [Accessed 16 November 2020].

Iso.org. 2014. Economic Benefits Of Standards. [online] Available at: $<$ https://www.iso.org/files/live/sites/isoorg/files/archive/pdf/en/ebs_case_studies_factsheets.pdf $>$ [Accessed 16 November 2020].

Osterwalder, A., Pigneur, Y., Smith, A., \& Clark, T. (2010). Business model generation. John Wiley \& Sons. 